\section{Active management of labour}

\section{True purpose has been misunderstood}

EDrTOR,-I wish to dispel any misunderstanding that may have arisen concerning the true purpose of active management of labour, ${ }^{1}$ introduced in the $B M F$ in $1969 .^{2}$ The purpose is to enhance the experience of childbirth for mothers, particularly first time mothers, whose need is greatest. ${ }^{3}$ The result has been that every expectant mother who attended this hospital during the past 25 yearsabout 150000-was given two firm assurances: that labour would not last longer than 12 hours and that a sympathetic nurse-midwife would afford personal attention throughout. The rate of caesarean section was not a motivating factor.

Rates of caesarean section did not become an issue until much later, and in a different context. In 1969 there were no substantial differences among institutions in Britain or between the two sides of the Atlantic; rates rarely exceed 5\% (of total births). Through the 1970s a fourfold increase occurred across the United States and the rate reached $20 \%$. This dramatic development had repercussions worldwide. Meanwhile an official inquiry identified dystocia as the main reason for the change. ${ }^{4}$ Seven times as many caesarean sections were being performed for this indication across the United States as in Dublin. The sharp contrast between the active approach to the management of labour adopted in Dublin and the passive approach pursued, contemporaneously, in the United States constituted strong, albeit inferential, evidence that active management of labour could offer a viable alternative to spiralling rates of caesarean section. ${ }^{5}$ The possibility remains that the adoption of some or all of the components of active management of labour by hospitals in Britain has exercised a restraining influence.

Several specific points merit further comment. James G Thornton and Richard J Lilford define active management of labour as a package of interventions in labour-namely, strict diagnostic criteria for labour, early amniotomy, early use of oxytocin, and continuous personal support. ${ }^{1}$ It is unfortunate that the first and the last of these should be classified under the emotive term "intervention." The criteria for diagnosing labour attributed to the National Maternity Hospital are not correct, while the authors imply that it would be preferable not to provide clear guidelines in respect of diagnosing labour, in which case first time mothers, their relatives, or indeterminate hospital staff would be left to make this crucial decision.

We prefer short letters that relate to a recently published article and we are unlikely to publish letters longer than 400 words and containing over five references. Letters may be shortened. Your letters should be typed with double spacing and include a word count. All authors need to sign the letter and provide one current appointment and address. We encourage you to declare any conflict of interest. Please enclose a stamped addressed envelope if you require an acknowledgment.
The authors do not mention that the purpose of early amniotomy is to ensure that dangerous concentrations of meconium are not concealed behind intact membranes before the cumulative strain of labour is brought to bear on the fetus; the procedure is not performed to shorten labour. Patients correctly informed on this score might well express a different preference with respect to timing. In practice, records show that spontaneous rupture of membranes occurs in one in three cases before admission. The authors also do no make clear that early oxytocin recommended for selective, not routine, use when progress is slow and only in first time mothers. ${ }^{7}$

Finally, I question whether the clinical material analysed in this study-given the small numbers, its fragmented nature, and poor compliance-is of sufficient quality to sustain any firm conclusion.

KIERAN O'DRISCOLI

National Maternity Hospital, Professor emeritus

Dublin 2,

Republic of Ireland

1 Thornton JG, Lilford RJ. Active management of labour: curren knowledge and research issues. $B M F$ 1994;309:366-9.

2 O'Driscoll K, Jackson JA, Gallagher JT. Prevention of prolonged labour. $B M F$ 1969; ii:477-80.

3 O'Driscoll K, Stronge J, Minogue M. Active management of labour. BMF 1973;iii:135-7.

4 National Institutes of Health. Caesarean childbirh: report of a consensus development conference. Bethesda. NIH, 1981. NIH consensus development conference.

5 O'Driscoll K, Foley M, MacDonald D. Active management of labour as an alternative to cesarean section for dystocia. Obstet Gynecol 1984;63:485-90.

6 O'Driscoll K, Coughlan M, Fenton V, Skelly M. Active management of labour: care of the fetus. BMf 1977;ii:1451-3. 7 O'Driscoll K, Meagher D, Boylan P. Active management of labour: the Dublin experience. London: Mosby 1993

\section{Continual audit is important}

EDrroR,-Active management of labour was introduced not with the intention of reducing rates of caesarean section but rather to reduce the incidence of prolonged labour. 'This it has done in the National Maternity Hospital, Dublin, and in most other studies without increasing rates of operative delivery-indeed, it has reduced this rate in some studies.

I suggest that James G Thornton and Richard J Lilford ${ }^{2}$ have failed to consider two components of active management of labour-namely, antenatal education and, in particular, strict audit by peer review. The organisational aspects of active management of labour, with all deliveries being assessed by one person and discussed at weekly meetings of senior midwifery and medical staff, lends itself well to the model of a continual cycle of medical audit. In this, small changes to management are continually being made and continuous audit ensures that all interventions are kept to the minimum. Indeed, this may be the most important ingredient of active management of labour.

The management of labour does not lend itself well to randomised controlled trials, as Thornton and Lilford point out with regard to the trials of amniotomy and early oxytocin. ${ }^{2}$ How appropriate is it to extrapolate results and conclusions from a randomised trial in one unit to another unit where not only the background intervention rates but also the training of the staff and the expectations of the women are different?

Before further large, expensive, and often inconclusive trials are performed it might be better to ensure that experienced staff work in labour wards $s^{3}$ and that continual local audit is used to determine standards and expectations; then appropriate changes in management could be instigated.

M S ROBSON Consultant obstetrician and gynaecologist

Wycombe General Hospital,

Wycombe Genera

Buckinghamshire HP11 2TT

1 O'Driscoll $\mathrm{K}$, Jackson RJA, Gallagher IT. Prevention of prolonged labour. $B M F$ 1969;ii:477-80.

2 Thornton JG, Lilford RJ. Active management of labour: current knowledge and research issues. BMF 1994;309:366-9. (6 August.)

3 Royal College of Obstetricians and Gynaecologists. Minimum standards of care in labour. Report of a working party, London: RCOG, 1994

\section{Standards vary among institutions}

EDITOR,-James G Thornton and Richard J Lilford's dissection of the package of active management of labour into its various components is like that of a mechanic trying to decide which component of a car's engine makes it go.' The authors fail to realise that it is the sum of the parts that makes active management of labour a highly skilled form of management that requires expert handling to be effective and safe. Meta-analysis of active management of labour can give meaningful results only when applied to the whole of the package delivered appropriately by expert staff. Different institutions are as likely to show different outcomes as two different models of cars are likely to give different performances.

Amniotomy and oxytocin are vital components to active management but are too often applied inappropriately: amniotomy may be deferred for several hours after the patient has been deemed to be in labour, oxytocin schedules may be arbitrarily altered, and infusions may be stopped and started in response to changes in the cardiotocograph without fetal blood sampling being done if fetal distress is suspected. The central role of the patient is often forgotten. Adequate antenatal education explaining the aims and methods of active management is essential to ensure patients' cooperation and compliance. Undoubtedly the increasing consumerism and legalisation of obstetric care will result in many changes in the traditional practice of active management of labour as originally defined by O'Driscoll and Meagher, ${ }^{2}$ but the core idea of a carefully orchestrated and audited expert team approach involving the patient, midwife, and obstetrician committed to achieving a safe and normal delivery for both mother and infant will remain.

JOHN F STRATTON

Department of Obstetrics and Gynaecology,

Northwick Park Hospital,

Harrow,

Middlesex

1 Thornton JG, Lilford RJ. Active management of labour: current knowledge and research issues. BMF 1994;309:366-9. (6 August.)

2 O'Driscoll K, Meagher D. Active management of labour. London: Saunders, 1980.

\section{Non-randomised studies cannot be ignored}

EDIToR,-James G Thornton and Richard J Lilford's assessment of the components of active management of labour is the equivalent of taking a 